DOI: https://doi.org/10.24127/ajpm.v8i1.1724

\title{
PEMAHAMAN KONSEP MATEMATIS MELALUI MODEL WEE DENGAN STRATEGI QSH DITINJAU DARI SELF REGULATION
}

\author{
Tri Wahyuni' ${ }^{1}$, Bambang Sri Anggoro ${ }^{2}$, Komarudin ${ }^{3}$ \\ 1,2,3 Pendidikan Matematika, Universitas Islam Negeri Raden Intan Lampung \\ E-mail: twahyuni49@yahoo.com ${ }^{1)}$ \\ ${\underline{\text { bambarudin@ @adenintan.ac.id }^{2)}}}^{2802 @ \text { yahoo.com }}{ }^{3)}$
}

Received 11 December 2018; Received in revised form 1 April 2019; Accepted 3 May 2019

\begin{abstract}
The purpose of this research were to find out the difference in effectiveness between WEE model with QSH strategy and conventional learning, the difference between high, medium and low Self Regulation, and the interaction between learning model and Self Regulation towards the student's ability of understanding mathematical concept. This research was Quasy Experiment, population were all of Class X Science SMAN 14 Bandar Lampung academic year 2018/2019. The sample class used were two classes by using technique Cluster Random Sampling. Hypothesis testing using two-way ANOVA with $\alpha=$ $5 \%$.The results of this research were: (1)WEE model with QSH strategy more effective than conventional model learning towards the student's ability of understanding mathematical concept. (2)The ability to understand mathematical concept with high Self Regulation is better than medium and low Self Regulation, whereas there was no difference between medium and low Self Regulation. (3)There was no interaction between learning model and Self Regulation towards the student's ability of understanding mathematical concept.
\end{abstract}

Keywords: WEE Model Learning; QSH strategy; Self Regulation; Understanding of Mathematical Concept.

\section{PENDAHULUAN}

Matematika adalah salah satu pelajaran yang melibatkan proses berpikir peserta didik dalam penyelesaian masalah menggunakan pemahaman matematis yang mereka peroleh (Karyanti \& Komarudin, 2017). Hal ini sesuai dengan salah satu tujuan pembelajaran matematika di sekolah menurut Permendiknas No. 22 yaitu untuk memaham konsep matematika, menjelaskan keterkaitan antar konsep dan mengaplikasikan konsep atau algoritma secara luwes, akurat, efisien, dan tetap dalam pemecahan masalah (Anggoro, 2016). Berdasarkan tujuan pembelajaran tersebut maka pemahaman konsep adalah salah satu kecakapan matematis yang harus dikuasai dalam pembelajaran matematika. Memahami konsep adalah kemampuan untuk memahami makna seperti mampu mengekspresikan suatu materi yang disajikan kedalam bentuk yang lebih dipahami, mampu menafsirkan dan mampu menerapkannya (Uslima, Ertikanto, \& Rosidin, 2018)

Berdasarkan observasi yang telah dilakukan di SMA N 14 Bandar Lampung diperoleh bahwa $48 \%$ peserta didik kelas $\mathrm{X}$ belum mencapai nilai KKM pada Ulangan Harian matematika. Salah satu yang menyebabkan adalah rendahnya kemampuan pemahaman konsep matematis peserta didik. Pemahaman konsep merupakan salah satu aspek yang penting dalam pembelajaran matematika. Menurut Zulkardi pelajaran 
matematika menekankan pada konsep (Murizal, Yarman, \& Yerizon, 2012). Artinya dalam mempelajari matematika peserta didik harus memahami konsep matematis terlebih dahulu agar dapat menyelesaikan soal-soal dan mampu mengaplikasikannya ke dunia nyata serta mampu mengembangkan kemampuan lainnya yang menjadi tujuan dari pembelajaran matematika.

Menurut Thomas Anderson (Anderson, 2013) dalam penelitiannya yang berjudul "Integrating Reading and Science Education: on Developing and Evaluating WEE Science" menyatakan bahwa model pembelajaran WEE dapat mendorong peserta didik untuk mengambil sikap kritis, mengajukan pertanyaan, menganalisis jawaban dan dapat mengembangkan pemikirannya tentang suatu konsep. Dikarenakan proses pembelajaran menggunakan model WEE meliputi 3 tahapan, yaitu Wondering, Exploring dan Explaining dimana pada setiap tahapan seluruhnya melibatkan peran aktif peserta didik. Dimulai dari membangun pertanyaan, kemudian mencari jawaban yang sekiranya dapat memenuhi atas pertanyaan mereka tersebut, kemudian memahaminya dan menyampaikannya kembali menggunakan kata-kata mereka sendiri. Melalui tahapan-tahapan seperti ini peserta didik akan lebih mudah memahami suatu konsep materi yang sedang dipelajari. Sehingga dapat disimpulkan pembelajaran WEE mampu memaksimalkan kemampuan pemahaman konsep matematis peserta didik. Keterbaruan yang dilakukan pada penelitian ini adalah model WEE ini diterapkan pada pelajaran matematika dan untuk mengamati efektivitasnya terhadap kemampuan pemahaman konsep matematis peserta didik.

Model pembelajaran WEE (Wondering, Exploring \& Explaining) adalah model pembelajaran yang dalam pelaksanaannya meliputi 3 tahap yaitu, Wondering (menimbulkan rasa ingin tahu atas beberapa hal yang mereka temukan setelah melakukan kegiatan membaca), Exploring (melakukan pencarian atas hal-hal yang ingin mereka ketahui tersebut) dan Explaining (memaparkan hasil eksplorasi mereka kepada peserta didik lainnya).

Menurut Intan (Permatasari, 2015) dalam penelitiannya yang bertujuan untuk mengetahui pengaruh strategi QSH terhadap hasil belajar peserta didik, menyatakan bahwa pembelajaran dengan strategi QSH memberikan hasil belajar yang lebih baik daripada pembelajaran yang tidak menggunakan strategi QSH. Keterbaruan yang dilakukan pada penelitian ini adalah strategi QSH dikombinasikan dengan model pembelajaran WEE untuk memaksimalkan kemampuan pemahaman konsep matematis.

Strategi QSH (Question Student Have) adalah strategi yang menuntut peserta didik untuk bertanya dalam tulisan. Tujuannya adalah untuk mendorong peserta didik untuk berpikir dalam memecahkan suatu masalah, menyelidiki dan menilai penguasaan peserta didik tentang bahan pelajaran, membangkitkan minat peserta didik untuk sesuatu sehingga akan menimbulkan keinginan untuk mempelajarinya dan juga menarik perhatian peserta didik dalam belajar (Rohaendi, 2017).

Secara umum, ada 2 faktor yang mempengaruhi prestasi belajar peserta didik yaitu factor eksternal dan factor internal. Faktor eksternal adalah factor dari luar seperti lingkungan keluarga, teman-teman dan sekolah. Sedangkan faktor internal adalah faktor yang berasal dari dalam diri peserta didik salah satunya adalah regulasi diri (Self Regulation). Peserta didik harus 
memiliki kemampuan untuk mengatur dan mengenali dirinya sendiri dalam proses pembelajaran, setidaknya peserta didik lebih tahu apa-apa yang disukai dan yang tidak disukainya, apa kekurangan dan kelebihan yang ada pada dirinya, dan tujuan atau target apa yang harus dicapai dalam pembelajaran tersebut. Kemampuan peserta didik mengatur dan mengenali dirinya sendiri ini disebut dengan Self Regulation.

Menurut Dede (Nahdi, 2017) dalam penelitiannya yang bertujuan untuk mengetahui pengaruh Self Regulation dalam pembelajaran matematika menyatakan bahwa Self Regulation memiliki pengaruh besar terhadap keberhasilan peserta didik dalam belajar. Keterbaruan yang dilakukan pada penelitian ini adalah Self Regulation digunakan untuk mengamati kemampuan pemahaman konsep matematis peserta didik.

Berdasarkan uraian tersebut maka penelitian ini bertujuan untuk mengetahui perbedaan efektivitas antara model WEE dengan strategi QSH dan model pembelajaran konvensional terhadap kemampuan pemahaman konsep matematis peserta didik, dan untuk mengetahui perbedaan antara peserta didik dengan Self Regulation tinggi, sedang dan rendah terhadap kemampuan pemahaman konsep matematis peserta didik, serta untuk mengetahui interaksi antara model pembelajaran dan Self Regulation terhadap kemampuan pemahaman konsep matematis peserta didik.

\section{METODE PENELITIAN}

Penelitian yang dilakukan adalah penelitian Quasy Experimental Design yaitu penelitian dengan kelas kontrol yang tidak dapat berfungsi sepenuhnya untuk mengontrol variabel-variabel luar yang mempengaruhi pelaksanaan eksperimen (Sugiyono, 2016) Rancangan penelitian eksperimentasi yang akan dilakukan disajikan pada Tabel 1.

Tabel 1. Rancangan Penelitian Eksperimentasi

\begin{tabular}{cccc}
\hline $\begin{array}{c}\text { Self Regulation } \\
\left(\boldsymbol{Q}_{\boldsymbol{j}}\right)\end{array}$ & $\begin{array}{c}\text { Tinggi } \\
\left(\boldsymbol{Q}_{\mathbf{1}}\right)\end{array}$ & $\begin{array}{c}\text { Sedang } \\
\left(\boldsymbol{Q}_{\mathbf{2}}\right)\end{array}$ & $\begin{array}{c}\text { Rendah } \\
\left(\boldsymbol{Q}_{\mathbf{3}}\right)\end{array}$ \\
$\begin{array}{cccc}\text { Model } \\
\text { Pembelajaran }\left(\boldsymbol{P}_{\boldsymbol{i}}\right)\end{array}$ & $P_{I} Q_{I}$ & $P_{I} Q_{2}$ & $P_{1} Q_{3}$ \\
\hline WEE denganStrategi QSH $\left(P_{1}\right)$ & $P_{2} Q_{I}$ & $P_{2} Q_{2}$ & $P_{2} Q_{3}$ \\
Konvensional $\left(P_{2}\right)$ & & &
\end{tabular}

\begin{aligned} & \hline Keterangan: \\ &$P_{I} Q_{I}=$ Model WEE dengan strategi \\ & QSH dengan Self Regulation \\ & tinggi \\ &$P_{I} Q_{2}=$ Model WEE dengan strategi \\ & QSH dengan Self Regulation \\ & sedang \\ &$P_{I} Q_{3}=$ Model WEE dengan strategi \\ & QSH dengan Self Regulation \\ & rendah \\ &$P_{2} Q_{1}=$ Model \\ & konvensional dengan Self \end{aligned}

$$
\begin{aligned}
P_{2} Q_{2}= & \text { Regulation tinggi } \\
& \text { Model penvensional dengan Self } \\
& \text { Regulation sedang } \\
P_{2} Q_{3}= & \text { Model pembelajaran } \\
& \text { konvensional dengan Self } \\
& \text { Regulation rendah. }
\end{aligned}
$$

Populasi yang digunakan pada penelitian ini adalah seluruh kelas $\mathrm{X}$ MIA SMA N 14 Bandar Lampung sebanyak 7 kelas. Dengan 
menggunakan teknik sampling Cluster Random Sampling diperoleh kelas sampel sebanyak dua kelas, yaitu kelas $\mathrm{X}$ MIA 5 sebagai kelas eksperimen (pembelajaran menggunakan model WEE dengan strategi QSH) dan kelas X MIA 6 sebagai kelas kontrol (pembelajaran konvensional).

Instrumen penelitian yang digunakan adalah tes kemampuan pemahaman konsep matematis dan angket Self Regulation. Adapun indicator kemampuan pemahaman konsep matematis peserta didik yang digunakan pada penelitian ini yaitu:

1) Peserta didik mampu menjelaskan kembali suatu konsep.

2) Peserta didik mampu mengklasifikasikan objek-objek matematika.

3) Peserta didik mampu memberikan contoh dan bukan contoh dari suatu konsep

4) Peserta didik mampu mengembangkan syarat perlu atau syarat cukup suatu konsep.

5) Peserta didik mampu menyajikan konsep dalam berbagai bentuk representasi matematis.

6) Peserta didik mampu mengaplikasikan konsep tersebut dalam pemecahan masalah matematika.

Sedangkan indikator yang digunakan sebagai pedoman dalam penyusunan skala angket Self Regulation adalah Goal setting, Self Instruction, Emotional Regulation, Self Monitoring, Self Evaluation dan Self Reflection.

Setelah melakukan uji coba pada instrumen, selanjutnya dihitung validitas dan reliabilitas untuk instrument angket dan dilanjutkan dengan perhitungan daya beda dan tingkat kesukaran untuk instrument tes pemahaman konsep. Teknik analisis data yang dilakukan adalah uji normalitas dan uji homogenitas. Uji normalitas menggunakan tes Liliefors dan uji homogenitas menggunakan uji Bartlet. Pengujian hipotesis pada penelitian ini menggunakan uji Anava Dua Jalan dan dilanjutkan dengan uji lanjut pasca Anava menggunakan metode Scheffe.

\section{HASIL PENELITIAN DAN PEMBAHASAN}

\section{Analisis Variansi Dua Jalan}

Uji analisis variansi dua jalan digunakan untuk mengetahui signifikan efek dan interaksi dua variable bebas terhadap satu variable terikat berdasarkan kategori pemahaman konsep matematis dan self regulation tinggi, sedang dan rendah. Rangkuman uji analisis variansi dua jalan disajikan pada Tabel 2.

Tabel 2. Rangkuman Analisis Variansi Dua Jalan

\begin{tabular}{lcccccc}
\hline \multicolumn{1}{c}{ SK } & JK & db & KT & $\mathbf{F}_{\text {hitung }}$ & F $_{\text {Tabel }}$ & Kesimpulan \\
\hline Baris & 1452,581 & 1 & 1452,581 & 7,201 & 4,007 & $H_{0}$ ditolak \\
Kolom & 1314,063 & 2 & 657,031 & 3,257 & 3,156 & $H_{0}$ ditolak \\
Interaksi & 412,157 & 2 & 206,079 & 1,022 & 3,156 & $H_{0}$ diterima \\
GALAT & 11698,949 & 58 & - & - & - & - \\
\hline TOTAL & 14877,750 & 63 & - & - & - & - \\
\hline
\end{tabular}

Berdasarkan Tabel 2. dapat disimpulkan sebagai berikut: (1) $H_{0 A}$ ditolak, kesimpulannya terdapat perbedaan efektivitas antara peserta didik yang memperoleh model pembelajaran WEE dengan QSH dan 
DOI: https://doi.org/10.24127/ajpm.v8i1.1724

peserta didik yang memperoleh pembelajaran konvensional terhadap kemampuan pemahaman konsep matematis peserta didik. (2) $H_{0 B}$ ditolak, kesimpulannya terdapat perbedaan antara peserta didik dengan Self Regulation tinggi, sedang dan rendah terhadap kemampuan pemahaman konsep matematis peserta didik. (3) $H_{0 A B}$ diterima, kesimpulannya tidak terdapat interaksi antara model pembelajaran dan Self Regulation terhadap kemampuan pemahaman konsep matematis peserta didik.

\section{Uji Lanjut Pasca Anava}

Uji lanjut penting dilakukan mengingat hasil uji anava menunjukkan $H_{0 A}$ dan $H_{0 B}$ ditolak. Rangkuman rataan marginal disajikan pada Tabel 3.

Tabel 3. Rangkuman Rataan Marginal

\begin{tabular}{lcccc}
\hline \multirow{2}{*}{ Model Pembelajaran } & \multicolumn{3}{c}{ Self Regulation } & Rataan \\
\cline { 2 - 4 } & Tinggi & Sedang & Rendah & Marginal \\
\hline WEE denganStrategi QSH & 87,33 & 81,26 & 80,43 & 83,01 \\
Konvensional & 85,83 & 72,84 & 63,14 & 73,94 \\
\hline Rataan Marginal & 85,58 & 77,05 & 71,79 & \\
\hline
\end{tabular}

$H_{0 A}$ ditolak, yang berarti terdapat perbedaan efektivitas antara peserta didik yang memperoleh model pembelajaran WEE dengan QSH dan peserta didik yang memperoleh pembelajaran konvensional. Selanjutnya untuk mengetahui model pembelajaran mana yang lebih efektif, tidak perlu dilakukan uji komparasi ganda antar baris karena cukup melihat rataan marginal kedua model pembelajaran tersebut pada Tabel. 3. Sehingga dapat disimpulkan bahwa model pembelajaran WEE dengan strategi QSH lebih efektif digunakan daripada model pembelajaran konvensional.

Model pembelajaran WEE dengan strategi QSH mengarahkan peserta didik untuk membangun rasa ingin tahu atas beberapa hal yang sedang dipelajari dan menuliskannya dalam bentuk pertanyaan. Selanjutnya secara berkelompok peserta didik mengeksplor sendiri jawaban atas pertanyaanpertanyaan tersebut melalui beberapa sumber, sehingga jawaban yang didapat nantinya akan ditulis dan disampaikan menggunakan bahasa yang lebih mudah mereka pahami. Serta peserta didik tersebut juga dapat menentukan apakah jawaban yang mereka dapatkan telah memenuhi rasa keingintahuan mereka. Jika ternyata jawaban yang mereka peroleh kurang memuaskan maka disinilah peran pendidik dibutuhkan untuk memberikan penjelasan dan mengklarifikasi atas jawaban yang telah mereka peroleh. Hal ini bersesuaian dengan penelitian yang telah dilakukan oleh Thomas Anderson mengenai model WEE yang menyatakan bahwa model WEE dapat melibatkan peran aktif peserta didik pada saat proses pembelajaran. Kemudian juga bersesuaian dengan penelitian yang telah dilakukan oleh Intan Dwi tentang strategi QSH yang menyatakan bahwa hasil belajar peserta didik menggunakan strategi QSH lebih baik daripada peserta didik yang tidak diberi strategi QSH. Sehingga dapat disimpulkan kemampuan pemahaman konsep matematis peserta didik yang menerima model WEE dengan strategi QSH akan lebih baik dari peserta didik yang menerima pembelajaran konvensional. 
DOI: https://doi.org/10.24127/ajpm.v8i1.1724

$H_{0 B}$ ditolak, yang berarti terdapat perbedaan antara peserta didik dengan Self Regulation tinggi, sedang dan rendah terhadap kemampuan pemahaman konsep matematis peserta didik. Oleh karena itu, komparasi ganda antar kolom dengan metode Scheffe perlu dilakukan untuk melihat manakah yang secara signifikan mempunyai rataan yang berbeda. Rangkuman uji komparasi ganda antar kolom disajikan pada Tabel 4.

Tabel 4. Rangkuman Uji Komparasi Ganda antar Kolom

\begin{tabular}{ccccc}
\hline No. & Interaksi & $\boldsymbol{F}_{\text {hitung }}$ & $\boldsymbol{F}_{\text {tabel }}$ & Kesimpulan \\
\hline 1 & $\left(\mu_{1}\right.$ vs $\left.\mu_{2}\right)$ & 4,107 & 4,007 & $H_{0}$ ditolak \\
2 & $\left(\mu_{1}\right.$ vs $\left.\mu_{3}\right)$ & 7,015 & 4,007 & $H_{0}$ ditolak \\
3 & $\left(\mu_{2}\right.$ vs $\left.\mu_{3}\right)$ & 1,407 & 4,007 & $H_{0}$ diterima \\
\hline
\end{tabular}

Pada kelompok rataan marginal Self Regulation tinggi $\left(\mu_{1}\right)$ dan Self Regulation sedang $\left(\mu_{2}\right)$ dinyatakan bahwa $H_{0}$ ditolak, yang artinya terdapat perbedaan kemampuan pemahaman konsep matematis antara peserta didik dengan Self Regulation tinggi dan sedang. Pada kelompok rataan marginal Self Regulation tinggi $\left(\mu_{1}\right)$ dan Self Regulation rendah $\left(\mu_{3}\right)$ dinyatakan bahwa $H_{0}$ ditolak, yang artinya terdapat perbedaan kemampuan pemahaman konsep matematis antara peserta didik dengan Self Regulation tinggi dan rendah. Sedangkan pada kelompok rataan marginal Self Regulation sedang $\left(\mu_{2}\right)$ dan Self Regulation rendah $\left(\mu_{3}\right)$ dinyatakan bahwa $H_{0}$ diterima, yang artinya tidak terdapat perbedaan kemampuan pemahaman konsep matematis antara peserta didik dengan Self Regulation sedang dan rendah.

Perbedaan ini dikarenakan peserta didik dengan Self Regulation akan menetapkan tujuan apa yang harus dicapai pada proses pembelajaran, dan akan mengatur strateginya sendiri sedemikian sehingga tujuan yang telah mereka tetapkan tersebut dapat tercapai. Peserta didik dengan Self Regulation tinggi mampu mengenali dirinya sendiri dan mengatur strategi belajar yang sesuai dengan kebutuhannya. Strategi belajar yang dimkasud antara lain penetapan tujuan pembelajaran yang harus dicapai, perencanaan pembelajaraan yang akan dilakukan untuk mencapai tujuan tersebut, dan pengaturan waktu belajar yang digunakan. Sehingga dapat disimpulkan semakin tinggi tingkat Self Regulation peserta didik maka akan semakin baik pula kemampuan pemahaman konsep matematis mereka. Sedangkan peserta didik dengan Self Regulation sedang dan rendah cenderung malas dan tidak bertanggung jawab dalam kegiatan belajarnya. Tidak adanya target atau tujuan yang mereka tetapkan pada proses pembelajaran membuat peserta didik hanya belajar sekenanya, tanpa strategi, perencanaan atau pengaturan diri lainnya.

$H_{O A B}$ diterima, yang artinya tidak terdapat interaksi antara model pembelajaran dan Self Regulation terhadap kemampuan pemahaman konsep matematis peserta didik. Hal ini dikarenakan Self Regulation adalah kemampuan individu yang dimiliki oleh masing-masing peserta didik untuk mengendalikan atau mengatur dirinya sendiri dalam proses pembelajaran. Terlepas dari model atau strategi apa yang diterapkan oleh pendidik pada saat 
proses pembelajaran, kemampuan individu peserta didik ini cukup memberikan peran besar terhadap hasil belajar yang diperoleh.

Hal ini bersesuaian dengan teori yang dikemukakan oleh Risa Rahayu dalam penelitiannya yang menyatakan bahwa adanya regulasi diri yang baik dalam diri peserta didik akan memberikan hasil belajar yang baik pula pada peserta didik tersebut (Rahayu, Yusmansyah, \& Utaminingsih, 2017). Semakin tinggi tingkat Self Regulation peserta didik, maka semakin baik pula kemampuan pemahaman konsep matematis peserta didik. Sehingga dapat disimpulkan terlepas dari model pembelajaran yang diterapkan, tidak terdapat interaksi antara kemampuan pemahaman konsep matematis dengan tingkatan Self Regulation peserta didik.

\section{KESIMPULAN DAN SARAN}

Berdasarkan hasil analisis data dan uji hipotesis menggunakan uji anava dua jalan dengan uji lanjutan komparasi ganda dapat disimpulkan bahwa model WEE dengan strategi QSH lebih efektif dari model pembelajaran konvensional terhadap kemampuan pemahaman konsep matematis. Terdapat perbedaan kemampuan pemahaman konsep matematis antara peserta didik dengan Self Regulation tinggi, sedang dan rendah. Namun tidak terdapat perbedaan kemampuan pemahaman konsep matematis antara peserta didik dengan Self Regulation sedang dan rendah. Tidak terdapat interaksi antara model pembelajaran dan Self Regulation terhadap kemampuan pemahaman konsep matematis peserta didik.

Berdasarkan hasil penelitian yang telah dilaksanakan, maka saran dari penelitian ini yaitu penggunaan model pembelajaran sebaiknya dapat menyesuaikan dengan materi yang akan disampaikan. Selanjutnya, pendidik harus mampu menngarahkan peserta didik pada setiap tahapan-tahapan dalam proses pembelajaran menggunakan model WEE dengan strategi QSH agar dapat memaksimalkan kemampuan pemahaman konsep matematis peserta didik.

\section{DAFTAR PUSTAKA}

Anderson, T. H., et.al. (2013). Integrating reading and science education: On developing and evaluating WEE Science. Journal of Curriculum Studies, 29(6).

Anggoro, B. S. (2016). Analisis Persepsi Siswa SMP terhadap Pembelajaran Matematika ditinjau dari Perbedaan Gender dan Disposisi Berpikir Kreatif Matematis. Al-Jabar: Jurnal Pendidikan Matematika, 7(2).

Karyanti, \& Komarudin. (2017). Pengaruh Model Pembelajaran KUMON Terhadap Pemahaman Matematis Ditinjau Dari Gaya Kognitif Peserta Didik. Prosiding Seminar Nasional Matematika Dan Pendidikan Matematika, 1(1).

Murizal, A., Yarman, \& Yerizon. (2012). Pemahaman Konsep Matematis dan Model Pembelajaran QUANTUM TEACHING. Jurnal Pendidikan Matematika, 1(1).

Nahdi, D. S. (2017). Self Regulated Learning sebagai Karakter dalam 
DOI: https://doi.org/10.24127/ajpm.v8i1.1724

Pembelajaran Matematika. Jurnal

THEOREMS (The Original

Research of Mathematics), 2(1).

Permatasari, I. D. (2015). Pengaruh

Metode Question Student Have

Terhadap Hasil Belajar Sejarah

Siswa Kelas XI IPS SMA Negeri 1

Ngimbang. AVATARA: E-Journal

Pendidikan Sejarah, 3(2).

Rahayu, R., Yusmansyah, \&

Utaminingsih, D. (2017).

Hubungan Antara Regulasi Diri

Dengan Prestasi Belajar Siswa

Kelas X. ALIBKIN: Jurnal

Bimbingan Konseling, 5(5).

Rohaendi, S. (2017). Penerapan Strategi

Pembelajaran Question Student

Have Untuk Meningkatkan

Kemampuan Komunikasi

Matematis Siswa SMK. Jurnal

Ilmiah FKIP Universitas Subang, 4(2).

Sugiyono. (2016). Metode Penelitian

Pendidikan. Bandung: Alfabeta.

Uslima, U., Ertikanto, C., \& Rosidin, U. (2018). Contextual Learning Module Based on Multiple Representations: The Influence on Students ' Concept Understanding. Tadris: Jurnal Keguruan Dan Ilmu Tarbiyah, 3(1). 